\title{
A sustentabilidade empresarial no mercado brasileiro: estudo de caso da empresa O Boticário
}

\author{
Fernanda Costa Demier Rodrigues \\ IFF - Instituto Federal Fluminense
}

\begin{abstract}
RESUMO
Vivemos em uma sociedade em que está se tornando inadmissível, no mundo dos negócios, o desrespeito ao meio ambiente e a falta de políticas de desenvolvimento sustentável em prol da interação negócio x meio ambiente. No período de 20 anos, entre a ECO92 e a Rio+20, inúmeras propostas nacionais e internacionais foram colocadas em prática para que houvesse uma adaptação das práticas industriais a uma postura de responsabilidade social. Nesta perspectiva, o desenvolvimento sustentável consiste em uma forma de interação entre o desenvolvimento econômico e o social que satisfaça as necessidades de determinada sociedade de determinada época, sem comprometer a capacidade das gerações futuras de suprir suas próprias necessidades. Este estudo propõe um aprofundamento sobre o tema em questão por meio da identificação de ações institucionais, que visam ao respeito ao meio ambiente e ao desenvolvimento sustentável tomadas pela empresa O Boticário. Como metodologia de trabalho, foi realizada inicialmente uma pesquisa de cunho bibliográfico com o intuito de promover um embasamento teórico e histórico maior sobre o tema de modo que este servisse para uma melhor concretização da segunda parte da pesquisa em que foi realizado um estudo de caso acerca das ações sustentáveis no sistema produtivo da empresa O Boticário. Constatou-se, ao final do estudo, que a sustentabilidade empresarial vem crescendo deste a Rio 92 tanto no Brasil quanto no mundo e a empresa O Boticário tem uma posição de destaque no contexto nacional em relação à prática de ações sustentáveis no processo produtivo.
\end{abstract}

Palavras-chave: Sustentabilidade. Sustentabilidade empresarial. O Boticário.

\begin{abstract}
We live in a society where the disrespect for the environment and the lack of sustainable development policies in favor of business x environment interaction are becoming inadmissible in the business world. In the 20-year period, between ECO92 and Rio +20 , numerous national and international proposals were put in place to adapt industrial practices to a socially responsible posture. In this perspective, sustainable development is a form of interaction between economic and social development that reaches the demands of a certain society at a specific time without compromising the ability of future generations to supply their needs. This graduation work proposes a further study on the theme, from the identification of social and environmental practices adopted by the company O Boticário. As the methodology of work, bibliographic research was carried out in order to promote a theoretical and historical background on the subject so that it could promote a better accomplishment of the second part of the research in which it was performed in a case study concerning sustainable actions in the productive system of the company O Boticário. At the end of the study, it could be noticed that corporate sustainability has been growing since Rio 92 both in Brazil and in the world and the company O Boticário has a prominent position in the national context in relation to the practice of sustainable actions in the production process.
\end{abstract}

Keywords: Sustainability. Corporate sustainability. O Boticário. 


\section{INTRODUÇÃO}

É fato que vivemos em uma sociedade em que está se tornando inadmissível, no mundo dos negócios, o desrespeito ao meio ambiente e a falta de políticas de desenvolvimento sustentáveis em prol da interação negócio $\mathrm{x}$ meio ambiente. A temática, que já vem sendo debatida no país há décadas, ganhou enfoque especial com a Conferência das Nações Unidas sobre o Meio Ambiente e Desenvolvimento, realizada no Rio de Janeiro na década de 90 e intitulada Rio 92 ou ECO $92^{1}$.

Neste evento, líderes mundiais se reuniram com a intenção de propor medidas que propiciassem um desenvolvimento sustentável por meio de um modelo de crescimento econômico menos consumista e mais adequado ao equilíbrio ecológico. A temática foi retomada e reavaliada com novas propostas em encontros posteriores até a Rio +20 , ocorrida em 2012 , nos mesmos moldes da primeira reunião, e cujo objetivo era renovar o compromisso político com o desenvolvimento sustentável.

Neste período de vinte anos, propostas em prol de um desenvolvimento sustentável nas empresas brasileiras foram sendo fortalecidas no país por meio de empreendedorismo empresarial e políticas públicas governamentais. Com isso, surgiram empresas visando a um bom relacionamento com a sociedade e com pretensão de se tornarem referência em suas áreas ao adotarem estratégias empresariais com um compromisso socioambiental.

Nesse contexto, de 1992 a 2002, a sustentabilidade empresarial e a responsabilidade social se evidenciaram em empresas de diferentes áreas que tentaram conciliar a defesa da natureza com o desenvolvimento econômico, em um novo modelo de economia que atendesse às necessidades e exigências de uma sociedade cada vez mais consciente da importância do cuidado com o meio que cerca os indivíduos.

Destaque especial se salienta em relação às empresas que têm, em sua linha de produção, produtos de beleza que, por trabalharem com grande consumo de água e energia no processo produtivo, além de desencadearem um considerável acúmulo de embalagens plásticas, são constantemente cobradas por ações sustentáveis. Neste conjunto específico, é possível ensejar o seguinte questionamento: É possível observar de forma eficaz a prática de ações sustentáveis em indústrias brasileiras de cosméticos?

Essa problemática constituiu a mola propulsora desta pesquisa uma vez que o aprofundamento acerca do tema pode contribuir para a identificação de práticas empresariais de cunho socioambientais que efetivamente obtiveram sucesso. Para este propósito, foi realizado um estudo de caso a respeito das práticas sustentáveis da empresa brasileira $\mathrm{O}$ Boticário, famosa rede de franquias de cosméticos e perfumes sediada no Paraná e em atividade no país deste 1977.

Tendo em vista as questões apresentadas, este estudo propõe um aprofundamento sobre o tema em questão por meio da identificação de práticas empresariais de cunho socioambientais eficazes da empresa O Boticário.

Para o alcance desse objetivo geral, foram estabelecidos os seguintes objetivos específicos: i) identificar e analisar propostas de sustentabilidade empresarial surgidas a partir da ECO 92; ii) identificar e analisar propostas de sustentabilidade empresarial a partir da Rio+92 iii) exemplificar estratégias eficazes de sustentabilidade da empresa de cosméticos brasileira O Boticário.

A metodologia foi focada inicialmente em uma pesquisa bibliográfica - tipo de pesquisa que abrange leitura, análise e interpretação de livros, periódicos etc. documentos mimeografados ou fotocopiados, mapas, imagens, manuscritos etc. com o objetivo conhecer as diferentes contribuições científicas disponíveis sobre determinado tema. Com isso, foi possível congregar dados e informações a serem utilizados ao longo da proposta de investigação sobre 
o tema. Para isso, foram selecionados estudos como os de Abramovay (2010), Brown (2009), dentre outros.

Na etapa seguinte, a investigação passa a apresentar o método de pesquisa estudo de caso, realizado por meio da coleta de dados secundários disponibilizados em ambiente virtual. Nesta parte, foram analisadas propostas de ações sustentáveis da empresa brasileira de cosméticos $\mathrm{O}$ Boticário a partir de informações coletadas no site oficial da companhia e de artigos científicos já publicados sobre tais práticas. As informações coletadas foram analisadas qualitativamente e refletiram fenômenos individuais sobre o tema da pesquisa colaborando para responder os questionamentos levantados na investigação.

Esta pesquisa está estruturada em cinco capítulos. No capítulo primeiro, a introdução, é apresentado o problema a ser discutido na pesquisa, os objetivos do estudo e a metodologia de trabalho a ser aplicada.

O segundo capítulo apresenta uma revisão de literatura acerca da temática central, enfocando conceitos básicos a respeito de sustentabilidade sob a perspectiva de diferentes autores.

O terceiro capítulo expõe uma evolução histórica da ideia de sustentabilidade desde a Conferência da Rio 92 até a Rio +20 .

O quarto capítulo engloba a apresentação e a análise de ações sustentáveis da empresa O Boticário.

Finalmente, no quinto capítulo, nas considerações finais, são expostos os resultados da pesquisa empreendida.

\section{REVISÃO DA LITERATURA}

A sustentabilidade já vem há algum tempo sendo um diferencial entre empresas no seu processo produtivo. Esta perspectiva de trabalho é vista com bons olhos pelo consumidor e pela sociedade de um modo geral e nasceu na década de 1950 com a noção de ecodesenvolvimento e aprimorou-se ao longo do tempo até o conceito de responsabilidade social e sustentabilidade empresarial propagados hoje.

\section{A urbanização e o ecodesenvolvimento}

Até por volta da década de 50, o Brasil concentrava sua economia na exportação de produtos agrícolas, sendo, por isso, um país predominantemente rural. Este perfil agrárioexportador se manteve de maneira quase imutável até 1930, quando se iniciou a construção de um modelo econômico urbano-industrial no país por meio do processo de industrialização e do consequente deslocamento da população do campo para a cidade em busca de melhores condições de trabalho (HOFF, 2008).

Com a industrialização promovida, na década de 50, pelos governos de Getúlio Vargas e Juscelino Kubitscheck, esse processo de urbanização se intensificou em todo o Brasil, acontecendo, em maior escala, nas regiões Sul e Sudeste e, em menor escala, nas ou tras regiões do país. Com isso, na década de 70, a maior parte da população brasileira já se encontrava em regiões urbanas onde a disponibilidade de emprego, saúde, educação e serviços era bem maior (HOFF, 2008).

Ressalta-se que o advento da urbanização ocorreu de forma rápida e desordenada no país, o que desencadeou consequências graves, tais como favelização, violência urbana, poluição e enchentes. Neste contexto, surgem questões que envolvem o acesso da população aos bens e recursos naturais concomitante ao desenvolvimento socioespacial das cidades e à proteção ambiental (HORBACH, 2005).

Deste contexto, visando superar perspectivas nas quais a natureza era evidenciada como mero meio de produção e de geração de riquezas e focar em paradigmas econômicos que envolvam a questão da proteção ambiental, surgiu, na década de 70, o conceito de ecodesenvolvimento como sendo um 
objetivo responder problemática da harmonização dos objetivos sociais e econômicos do desenvolvimento com uma gestão ecologicamente prudente dos recursos e do meio (MONTIBELLER FILHO, 1993, p. 132).

Sachs (1986) assinala o conceito como um projeto de sociedade ao definir que o ecodesenvolvimento trata "de gerir a natureza de forma a assegurar aos homens de nossa geração e a todas as gerações futuras a possibilidade de se desenvolver" (SACHS, 1986, p. 14). Nota-se uma perspectiva de atendimento às necessidades fundamentais da população de uma forma que os recursos naturais não se extingam e possam atender também às próximas gerações.

Em linhas gerais, então, o ecodesenvolvimento propunha, por meio da utilização de novas tecnologias, uma adequada articulação dos recursos naturais aos padrões socioculturais dos diferentes grupos humanos visando o futuro da sociedade. A proposta ia de encontro às práticas da sociedade industrial e, por conta de um contexto mundial de expansão do capitalismo à época, a ideia não se concretizou (SACHS, 1986).

Após este período de questionamentos iniciais acerca da interação entre meio ambiente e sociedade, o assunto volta a ser debatido em eventos mundiais com a nomenclatura de sustentabilidade como será visto no capítulo seguinte.

\section{Desenvolvimento Sustentável/ Sustentabilidade}

Posteriormente, o termo ecodesenvolvimento foi substituído por desenvolvimento sustentável ou sustentabilidade, de forma ampla e popularizada, nas décadas de 80 e 90 . Cabe, neste contexto, informar que

Sua origem advém do relatório da Comissão de Brutland, de 1987. Este documento, produzido pela Comissão Mundial sobre o Meio Ambiente e o Desenvolvimento, e intitulado Nosso Futuro Comum, concebia o desenvolvimento sustentável como "o desenvolvimento que satisfaz as necessidades presentes, sem comprometer a capacidade das gerações futuras de suprir suas próprias necessidades" (WCED, 1997).

Considerando que a problema da pobreza é algo inevitável na sociedade, o relatório ressaltava a necessidade do atendimento às necessidades básicas da população, visando oferecer-lhes a possibilidade de melhores condições de vida numa perspectiva de equidade em prol do desenvolvimento urbano igualitário a todos os indivíduos. Neste contexto, a pobreza era vista como um problema ambiental e os caminhos para a sua solução constituem também a busca da sustentabilidade.

Dovers e Handmer (1992), por sua vez, discorrem, de maneira mais detalhada acerca dos conceitos de sustentabilidade e de desenvolvimento sustentável ao assinalarem que este trata da capacidade de o homem em sociedade resistir e adaptar-se a mudanças exógenas (desencadeadas por fatores externos ao indivíduo) e endógenas (desencadeadas por fatores internos do indivíduo) em prol de alcançar o seu objetivo final, que é a sustentabilidade do meio em que vive.

Ampliando o conceito, para Sachs (1993), existem cinco dimensões de desenvolvimento sustentável, a saber: i) Sustentabilidade social - desenvolvimento baseado na construção de uma sociedade com equidade, distribuição de renda justa e diminuição de desigualdades sociais por meio da melhoria dos padrões de vida e dos direitos sociais; ii) Sustentabilidade econômica - destinação e gestão mais eficientes dos investimentos públicos e privados, assim como do acesso à ciência e à tecnologia; iii) Sustentabilidade ecológica - redução do uso de combustíveis fosseis e aumento da utilização de tecnologia para a produção de novos recursos naturais; iv) Sustentabilidade Espacial - mudança na configuração dos espaços em prol da maximização de sua utilização e da proteção dos ecossistemas; v) Sustentabilidade cultural - mudanças na comunidade cultural, traduzindo o conceito normativo de desenvolvimento sustentável em uma pluralidade de soluções particulares.

Para Carvalho e Viana (1998), há três grandes dimensões no desenvolvimento sustentável, que são: o crescimento econômico, a equidade social e o equilíbrio ecológico. Esta visão evidencia a necessidade de que a tomada de decisões no mundo econômico, no mundo 
social e no mundo ambiental deva ser de igual importância. Trata-se do chamado triple bottom line (TBL), ou tripé de sustentabilidade. Nesta perspectiva, então, o progresso é compreendido como, além da ampliação da riqueza, maior benefício social e ecológico na mesma proporção.

Ainda em relação ao TBL, ressalta-se que, apesar de este conceito ter sido criado inicialmente com associação à gestão de negócios, caminha para uma mudança de paradigma por meio da qual passa a se vincular a uma mentalidade baseada na unidade planetária, sendo, por isso, também utilizado na esfera pública (Elkington, 2020). Mais especificamente no Brasil, TBL se relaciona ao princípio constitucional da responsabilidade do Poder Público para a desenvolvimento sustentável e inclusivo. (Freitas, 2016).

Horbach (2005) discute a sustentabilidade como uma confluência de três diferentes interesses ou conflitos, a saber: (i) a sustentabilidade econômica, caracterizando o interesse da geração atual em melhorar a suas reais condições de vida (ii) a sustentabilidade social, sendo esta a busca de uma equalização das condições de vida entre ricos e pobres, (iii) e sustentabilidade atual, evidenciando os interesses das gerações futuras que não estão comprometidas pela satisfação das necessidades da geração atual.

Mueller (2007) associa o desenvolvimento sustentável ao crescimento econômico da mesma forma que Ayres (2008). Para aquele, o capital físico oriun do das relações demográficas caminha em conjunto com o desenvolvimento tecnológico das organizações; para este, os seres humanos são responsáveis para com o outro e as futuras gerações e devem agir em prol do crescimento econômico baseado na justiça social e na eficiência no que diz respeito ao uso de recursos naturais. Importante ressaltar a necessidade de se estabelecerem políticas púbicas de fortalecimento de comunidades pequenas por meio da interação dos sistemas econômicos, sociais e ambientais com vistas ao cumprimento de objetivos para o alcance do desenvolvimento sustentável (FREITAS, 2016; SACHS, 2017).

Nota-se que a temática acerca do desenvolvimento sustentável e da sustentabilidade é complexa, evidenciando um processo dinâmico em que a convivência harmoniosa entre sociedade e meio ambiente se configura como seu objetivo primordial. E para que seja alcançado, constantes inovações devem ser empregadas nas esferas econômicas, políticas, sociais, culturais, educacionais etc. como forma de uma melhor integração entre todos os parceiros deste processo.

\section{A sustentabilidade empresarial: responsabilidade social e responsabilidade ambiental}

É fato que o desenvolvimento econômico de um país desencadeia, na maior parte das vezes, um custo ambiental, o qual, apesar de ocorrer de forma distinta de acordo com o ramo de atividade em que a empresa estiver inserida, está intrinsecamente associado ao estágio tecnológico do setor em questão, ao tipo de matéria-prima que serve de base à produção e a energia utilizada neste processo.

Neste contexto, vem crescendo por conta da exigência do próprio mercado, de estratégias empresárias que sinalizem preocupação ambiental. Trata-se da chamada responsabilidade social corporativa, perspectiva segundo a qual a empresa não deve visar apenas ao lucro, mas também à contribuição social para o meio em que se insere por meio e medidas que tragam cultura e melhorias para a sociedade (RAMOS, 1989).

Robbins (2000) assinala que uma empresa socialmente responsável age para além do cumprimento das leis, do pagamento de impostos e dos cuidados de segurança junto a seus colaboradores. Para o autor, uma empresa que seja efetivamente responsável na perspectiva social adota políticas que desencadeiam comportamentos e ações que agregam valor à empresa uma vez que colaboram para o desenvolvimento contínuo dos indivíduos, das comunidades em que se localizam e do seu relacionamento com o meio ambiente.

Dowbor (1998) associa a responsabilidade social das empresas a dois fatores centrais: ética e transparência. O primeiro prevê que as decisões tomadas pela empresa devem respeitar os direitos, os valores e os interesses de todos os indivíduos que porventura venham a ser afetados por elas. Já o segundo, assinala que a empresa deve atender às expectativas sociais, existindo coerência entre o seu discurso e a sua prática e, de forma alguma, ocultar informações importantes sobre seus produtos e serviços. 
Amaro e Caser (2004) estendem a ideia de sustentabilidade às empresas assinalando que, como ela se relaciona à noção de existência, de continuidade de vida a longo prazo, pode, por isso, se referir tanto a qualquer ser vivo quanto a qualquer organização. E ainda enfatiza que o desenvolvimento sustentável no âmbito organizacional deve ser entendido por meio de uma visão multidimensional, formada por três dimensões que se articulam entre si. São elas: a econômica (crescimento), a social (coesão) e a ambiental (proteção ou preservação).

A proposta de Amaro e Caser (2004) é corroborada por inúmeros autores. Dentre eles, é possível destacar a figura proposta por Coral (2002) e apresentado em seguida:

Figura 1. Modelo de sustentabilidade empresarial para cada uma das dimensões

\section{SUSTENTABILIDADE}
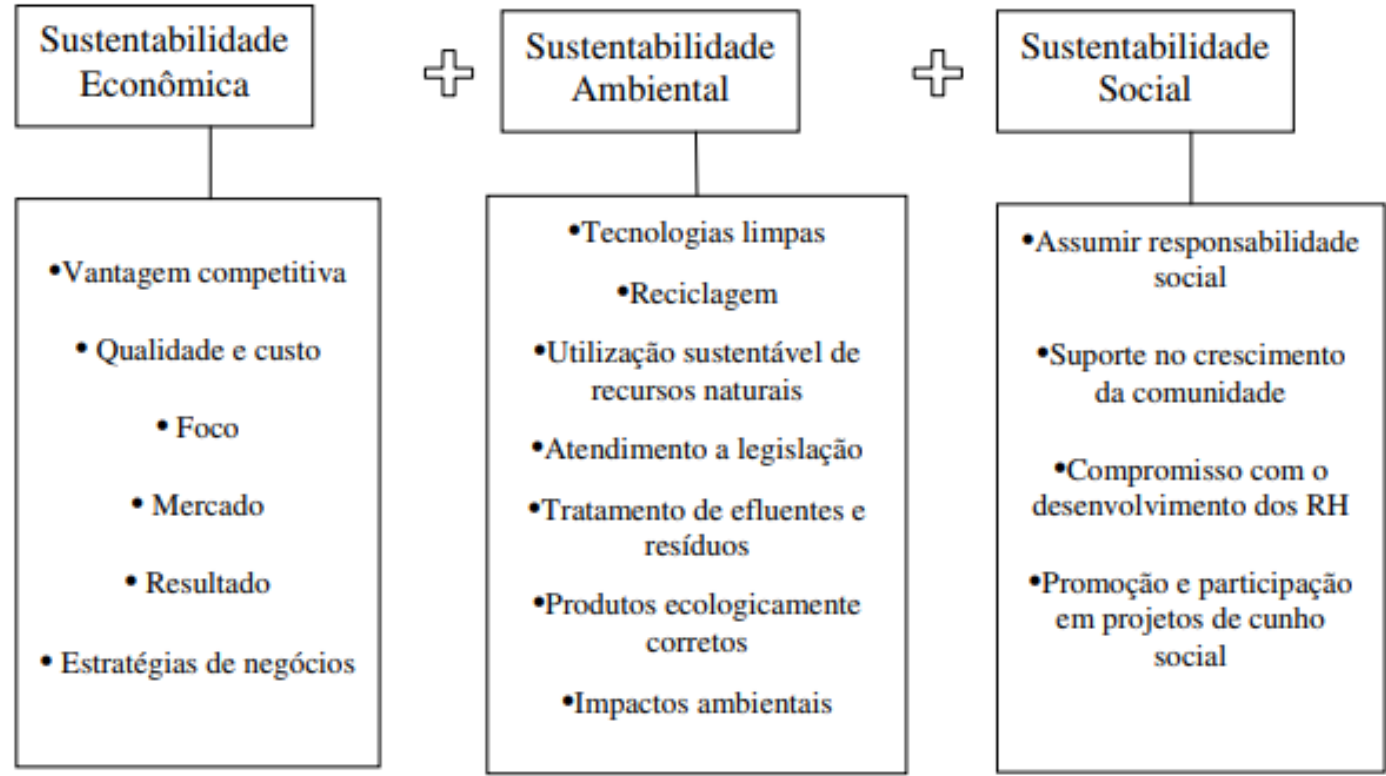

Fonte: Coral (2002)

Nota-se, neste modelo, as premissas que subjazem as políticas de desenvolvimento sustentável no mundo empresarial. No campo da sustentabilidade econômica, evidenciam-se objetivos que refletem o bem-estar de qualquer empresa que visa ao seu crescimento. No campo da sustentabilidade ambiental, aparecem questões que envolvem não só o cumprimento das normas legais voltadas à proteção do meio a mbiente como também a preocupação da ocorrência de situações imprevistas que causem impactos ambientais. No campo da sustentabilidade social, há a busca por melhorias sociais efetivas. É a composição conjunta destes três pilares que se constrói a sustentabilidade no mundo empresarial.

Em estudos mais recentes, o conceito de sustentabilidade é aprofundado e esmiuçado de forma mais detalhada com a sua vinculação a uma proposta de gestão empresarial cujo enfoque é fazer com que os resultados da produção se adequem aos recursos ambientais do meio que o processo ocorre visando a um desenvolvimento sustentável (LEWIS \& LEWIS, 2015).

\section{Evolução histórica: de Estocolmo ao Rio de Janeiro}

A No período de 5 a 15 de julho de 1972, visando à conscientização da sociedade acerca de uma melhor relação do homem com o meio ambiente e ao atendimento das necessidades da população à época e das gerações futuras por consequência, ocorreu, em Estocolmo, na Suécia, a Conferência das Nações Unidas sobre o Meio Ambiente Humano, também conhecida como Conferência de Estocolmo (HOFF, 2008).

Organizado pela ONU, este evento constituiu o primeiro grande encontro de chefes de 
estado do mundo, com a presença de cerca de 400 instituições governamentais e não governamentais e participação de 113 países. Em uma época em que se acreditava que o meio ambiente era uma fonte de recursos inesgotáveis que servia à satisfação dos desejos de conformo e consumo do homem, a Conferência mudou este pensamento tão comumente compartilhado ao evidenciar a necessidade de melhorar as relações do homem com o meio ambiente por meio da busca por equilíbrio entre desenvolvimento econômico e redução da degradação ambiental (HOFF, 2008).

A recepção das propostas da Conferência de Estocolmo foi variada. Enquanto os Estados Unidos se dispuseram a reduzir por um tempo com as atividades industriais e realizaram estudos sobre as condições da natureza, denominados "desenvolvimento zero", os países subdesenvolvidos, incluindo neste contexto o Brasil, não concordaram em diminuir suas atividades industriais, por conta de sua base econômica ser focada na industrialização. Daí, o chamado "desenvolvimento a qualquer custo" defendido por este grupo de países (SACHS, 1993).

O debate acerca da relação do homem com o meio ambiente foi retomado pela ONU, em 1983, uma comissão com o objetivo de avaliar as mudanças que efetivamente se concretizaram pelo mundo 10 anos da Conferência de Estocolmo. Os resultados obtidos por esta proposta foram compilados e divulgados em 1987 em um documento intitulado Nosso Futuro Comum ou Relatório Brundtland, o qual concebia o desenvolvimento sustentável como "o desenvolvimento que satisfaz as necessidades presentes, sem comprometer a capacidade das gerações futuras de suprir suas próprias necessidades" (WCED, 1997).

Com perspectiva bastante inovadora para aquela época, o documento evidenciou, mais uma vez, a necessidade de uma nova relação entre o homem e o meio ambiente de forma que o crescimento econômico se conciliasse com questões ambientais e sociais. Segundo o Relatório (WCED, 1997), uma série de medidas deviam ser tomadas pelos países para promover o desenvolvimento sustentável. Entre elas:

- limitação do crescimento populacional;

- garantia de recursos básicos (água, alimentos, energia) a longo prazo;

- preservação da biodiversidade e dos ecossistemas;

- diminuição do consumo de energia e desenvolvimento de tecnologias com uso de fontes energéticas renováveis;

- aumento da produção industrial nos países não-industrializados com base em tecnologias ecologicamente adaptadas;

- controle da urbanização desordenada e integração entre campo e cidades menores;

- atendimento das necessidades básicas (saúde, escola, moradia).

Em âmbito internacional, as metas propostas pelo relatório da WCED (1987) seriam:

- adoção da estratégia de desenvolvimento sustentável pelas organizações de desenvolvimento (órgãos e instituições internacionais de financiamento);

- proteção dos ecossistemas supranacionais como a Antártica, oceanos etc. pela comunidade internacional;

- banimento das guerras;

- implantação de um programa de desenvolvimento sustentável pela Organização das Nações Unidas (ONU).

Em 1985, por conta da preocupação das possíveis consequências advindas da redução da camada de ozônio na Terra, chefes de estado de diferentes países, reunidos na Áustria, em um evento chamado Convenção de Viena para a Proteção da Camada de Ozônio estabeleceram uma série de ações visando à proteção da camada de ozônio. Deste encontro, surgiu o Protocolo de Montreal sobre Substâncias que Destroem a Camada de Ozônio, tratado internacional que entrou em vigor em $1^{\circ}$ de janeiro de 1989 e no qual são elencadas obrigações específicas acerca da progressiva redução da produção e consumo das Substâncias que Destroem a Camada de Ozônio (SDOs) até sua total eliminação. Por meio do Decreto n 99.280, de 06 de junho de 1990, 
o Brasil aderiu ao Protocolo, ratificando e promulgando todas as emendas do texto-base (REI \& CARVALHO, 2012).

\section{A ECO 92}

Em 1992, com a organização das Nações Unidas, aconteceu, no Rio de Janeiro, a Conferência das Nações Unidas sobre o Meio Ambiente e o Desenvolvimento, também conhecida como ECO 92 ou Rio 92. Vinte anos após a primeira conferência sobre o meio ambiente, a ECO 92 reuniu representantes de 178 países com a intenção de propagar a ideia do desenvolvimento sustentável como um modelo de crescimento econômico menos consumista e adequado ao equilíbrio ecológico (ONU, 2021).

A convenção no Rio de Janeiro produziu relevantes documentos em prol da mudança de postura com o meio ambiente. Um deles foi a chamada Carta da Terra, uma declaração que apresenta princípios fundamentais para a construção de uma sociedade global justa, sustentável e pacífica no século XXI. Outros dois foram: a Declaração de Princípios sobre Florestas - uma declaração que apresenta os princípios a serem seguidos para a gestão, a conservação e o desenvolvimento sustentável de florestas de todos os tipos; e a Declaração do Rio sobre Meio Ambiente e Desenvolvimento - uma declaração em que se busca soluções para quatro tipos de problemas ambientais: a redução da produção de produtos contaminantes ou tóxicos; maior utilização de energias não contaminantes e renováveis; o apoio por parte dos governos ao transporte público, para reduzir o trafego de veículos e assim a contaminação por CO2 e o ruído; a escassez de água potável em diferentes partes do planeta, e soluções de como poupar esse recurso.

Além dessas de declarações, foram produzidas também três convenções, a saber: i)a Convenção sobre Diversidade Biológica - um tratado internacional que aborda regras para a proteção e do uso da diversidade biológica no mundo a partir de três objetivos: a conservação da diversidade biológica, o seu uso sustentável e a distribuição justa e equitativa dos benefícios advindos do uso econômico dos recursos genéticos, respeitada a soberania de cada nação sobre o patrimônio existente em seu território; ii) a Convenção das Nações Unidas de Combate à Desertificação - um tratado de combate ao fenômeno da desertificação; iii) a ConvençãoQuadro das nações Unidas sobre a Mudança do Clima (CQNUMC) - um tratado internacional cujo objetivo é a estabilização da concentração de gases do efeito estufa (GEE) na atmosfera em níveis tais que evitem a interferência perigosa com o sistema climático (ONU, 2021).

No entanto, o principal documento desenvolvido na ECO 92 foi a chamada Agenda 21. Esta enfatizou a necessidade de todos os governos, empresas, organizações não governamentais (ONGs) e setores da sociedade cooperarem em prol de soluções para problemas ambientais. Nesta perspectiva, foi estabelecida uma nova interpretação acerca do que se configura como progresso, levando em conta uma maior harmonia e equilíbrio holístico entre o todo e as partes, promovendo também a qualidade, e não apenas a quantidade do crescimento. Entre as principais metas destes documentos, podem-se destacar: a universalização do saneamento básico e do ensino; a maior participação das ONGs, dos sindicatos e dos trabalhadores na vida da sociedade, o planejamento e o uso sustentado dos recursos do solo, das formações vegetais e dos rios, lagos e oceanos; e a conservação da biodiversidade (BRASIL, 2003).

Em relação ao Brasil, as resoluções mais relevantes da Agenda 21 tomadas pelo país foram as seguintes: programas de inclusão social visando ao cesso de todos os brasileiros à educação, saúde e distribuição de renda, projetos de sustentabilidade ambiental tanto na área urbana quanto na rural, propostas de preservação dos recursos naturais e minerais e a exigibilidade de ética política para o planejamento de um país com desenvolvimento sustentável (BRASIL, 2003).

\section{Pós ECO 92}

A Após a ECO 92, uma série de eventos foram promovidos pela ONU como desdobramentos da cúpula do meio ambiente ocorrida no Rio de Janeiro.

Em 1997, aconteceu a Cúpula da Terra +5, cujo fito era revisar e avaliar as ações de implementação da Agenda 21, além de fazer recomendações acerca da adoção de metas 
juridicamente vinculativas para reduzir o feito estufa. Padrões sustentáveis de distribuição de energia e a ênfase na erradicação da pobreza como pré-requisito para o desenvolvimento sustentável foram outros temas discutidos no evento (ONU, 2021).

Em 1999, aconteceram a Segunda Conferência da ONU sobre Assentamentos Humanos em Instambul e a Sessão especial da Assembleia da ONU sobre Pequenos Estados Insulares em Desenvolvimento em Nova York. Em ambos os, foram discutidos os princípios do desenvolvimento sustentável (ONU, 2021).

Em 2002, visando avaliar conquistas, desafios e novas questões surgidas após a Cúpula da Terra, aconteceu em Joanesburgo a Cúpula Mundial sobre Desenvolvimento Sustentável. Neste evento, foram discutidas formas para que as metas da Agenda 21 se tornassem ações mais concretas e tangíveis (ONU, 2021).

Em 2005, foi realiza, nas Ilhas Maurício, o evento nomeado Estratégia Maurício, no qual a comunidade internacional discutiu questões do tipo: "mudanças climáticas e elevação do nível do mar; desastres naturais e ambientais; gestão de resíduos; recursos costeiros, marítimos, de água doce, terrestres, energéticos, turísticos e de biodiversidade; transporte e comunicação; ciência e tecnologia; globalização e liberação do comércio; produção e consumo sustentável; desenvolvimento de capacidade e educação para o desenvolvimento sustentável; saúde; cultura; gestão do conhecimento e da informação para tomada de decisão" (ONU, 2021) .

Em uma ação para concretizar o desenvolvimento sustentável como uma prática contínua, a ONU declarou o período entre 2005 e 2014 como a Década das Nações Unidas da Educação para o Desenvolvimento Sustentável. Esta decisão foi tomada com o intuito de "ajudar as populações a desenvolverem atitudes, habilidades e conhecimento para tomarem decisões informadas para o benefício próprio e dos outros, agora e no futuro, e para agirem sobre essas decisões" (ONU, 2021).

Em prol da promoção do desenvolvimento sustentável, um conjunto de órgãos ativos da ONU age em projetos contínuos, ora em conjunto, ora de modo individual. São eles: o Banco Mundial, o Programa das Nações Unidas para o Desenvolvimento (PNUD), a Organização Marítima Internacional (OMI), a Organização das Nações Unidas para o Desenvolvimento Industrial (UNIDO), a Organização das Nações Unidas para Agricultura e Alimentação (FAO) e o Programa das Nações Unidas para Assentamentos Humanos (ONU-HABITAT).

Em 2014, aconteceu a primeira edição da Assembleia Ambiental das Nações Unidas (a mais relevante plataforma da ONU para a discussão de questões ambientais - UNEA, em inglês). Este evento foi um marco para a temática de que o meio ambiente deve ser considerado um problema de todos da mesma forma que temas paz, segurança, finanças, saúde e comércio (ONU, 2021).

Em 2015, foi realizada, em Nova York, a Cúpula de Desenvolvimento Sustentável, onde o conjunto de países participantes definiu os novos Objetivos de Desenvolvimento Sustentável (ODS). Estes constituem parte de uma nova agenda de desenvolvimento sustentável baseada no tripé "prosperidade, pessoas e planeta e chamada Agenda 2030 para o Desenvolvimento Sustentável (ONU, 2021).

É válido ressaltar que, neste conjunto de eventos internacionais, segundo Cordani et al. (2019), o grande avanço de desenvolvimento sustentável ocorrido no Brasil após a ECO 92 foi a incorporação pelo poder público de novos conceitos de desenvolvimento. Neste contexto, destacaram-se o ISO 14000, série de normas que determinam diretrizes para garantir que empresas pratiquem a gestão ambiental; a implantação do CPTEC (Centro de Previsão de Tempo e Estudos Climáticos); a criação de projetos estaduais como o PROCLIMA (Programa Estadual de Mudanças Climáticas) em São Paulo que promove cursos, seminários, palestras e publicações sobre meio ambiente; e o surgimento da ANAMMA (Associação Nacional de Órgão Municipais em Meio Ambiente) que consolida a adoção de políticas públicas no âmbito dos municípios.

\section{Rio + 20: um novo começo}

Vinte anos depois da ECO 92, o Rio de Janeiro sediou novamente um evento mundial sobre o meio ambiente, em 2012, chamado Conferência das nações Unidas sobre 
Desenvolvimento Sustentável ou Rio+20. O objetivo principal deste encontro foi a renovação do compromisso político com o desenvolvimento sustentável avaliando os avanços obtidos deste 1992 e tratando de novos e emergentes temas. Assim, a Conferência teve dois temas centrais: a economia verde no contexto do desenvolvimento sustentável e da erradicação da pobreza; e estrutura institucional para o desenvolvimento sustentável.

O desenvolvimento sustentável, como já evidenciado anteriormente, sendo a capacidade de suprir as necessidades da geração atual sem comprometer a capacidade de atender às necessidades das futuras gerações, visa evitar o gasto e o desperdício desenfreado dos recursos naturais tão imprescindíveis para a vida do ser humano. A economia verde se encaixa neste contexto por constituir o conjunto de processos produtivos da sociedade e as tra nsações deles decorrentes que contribuam cada vez mais para o desenvolvimento sustentável, tanto nos aspectos sociais quanto ambientais (ABRAMOVAY, 2010).

A ONU assinala que a Economia Verde pode ser conceituada como um tipo de economia que propicia uma melhoria do bem-estar das pessoas em decorrência de uma maior preocupação com a equidade social, com os riscos de danos ao meio ambiente e com a escassez dos recursos naturais.

\section{Segundo a Constituição do Brasil:}

Art. 225. Todos têm direito ao meio ambiente ecologicamente equilibrado, bem de uso comum do povo e essencial à sadia qualidade de vida, impondo-se ao Poder Público e à coletividade o dever de defendê-lo e preservá-lo para as presentes e futuras gerações (BRASIL, 2005).

Conforme se observam nas passagens anteriores, verifica-se que a questão da responsabilidade ambiental, cuja temática foi trazida à tona na ECO 92 e enfatizada de maneira mais pontual na Rio +20 , vai muito além do papel de empresas com estratégias socioambientais. A questão abarca um posicionamento dos cidadãos e dos governos diante de uma temática tão importante. O Governo de São Paulo, por exemplo, já vinha assinalando, desde o ano de 2010, esta postura em seus documentos oficiais que analisaram a interação entre desenvolvimento, meio ambiente e qualidade de vida no Estado:

I- Privilegiar os setores mais "verdes" mediante subsídios e incentivos fiscais de modo que os investimentos privados sejam dirigidos a eles; II- Estabelecer regras que proíbam o exercício de determinadas práticas ou atividades nocivas ao meio ambiente; III- Aprovar regulamentação para determinadas ferramentas de mercado que ajudem na conservação do meio natural, entre os quais os impostos e direito de emissão (SÃO PAULO, 2010, p. 8).

Para Brown (2009, p. 4), "a solução para a construção de uma economia global apta a sustentar o progresso econômico é a criação de um mercado honesto, que diga a verdade ecológica". Assim, é preciso "reestruturar o sistema tributário, reduzindo os impostos sobre o trabalho e aumentando-os sobre as emissões de carbono e em outras atividades ambientalmente destrutivas. É urgente incorporar esses custos indiretos no preço de mercado”. Este posicionamento, já assinalado por Brown anos antes da Rio+20, se refletiu na Conferência de 2012 na perspectiva de que se considerou que o estado de desenvolvimento de um povo não poderia mais ser avaliado apensa pelo seu PIB (produto interno bruto), mas também seria necessário que houvesse avaliação em pilares econômicos, sociais e ambientais presentes na sociedade.

Dois pontos bastante positivos da Rio+20, que podem ser considerados grandes avanços. Um deles foi o crescimento do Programa das Nações Unidas para o Meio Ambiente (PNUMA) por meio da ONU que se comprometeu a agir como autoridade responsável pela agenda ambiental global. Neste contexto, o Conselho Gestor do PNUMA tornou-se mais responsivo, transparente e democrático uma vez que estendeu a possibilidade de participação a todos os países. Outro avanço foi o surgimento do Fórum Político de Alto Nível, cujas metas eram a promoção do debate contínuo a respeito da agenda ambiental internacional, o acompanhamento da implementação dos compromissos internacionais assumidos pelos países e o compartilhamento das melhores práticas e experiências em matéria de proteção ambiental.

O documento final da Rio+20 assinalou compromissos acerca da erradicação da pobreza, da segurança alimentar e nutricional, do saneamento básico, das cidades sustentáveis, da 
redução de riscos de desastres, da mudança do clima, da biodiversidade e da educação, entre dentre vários outros temas. Além disso, outro resultado a ser salientado diz respeito aos Objetivos de Desenvolvimento Sustentável (ODS), tema sensível no encontro por conta de posturas díspares entre os países acerca deles, mas que, ao final, teve um efeito positivo porque a ONU se comprometeu a aplicar tais objetivos para a análise do desenvolvimento dos países a partir de 2015 (BRASIL, 2012).

Anos após a Rio +20 , em um contexto que mira uma veiculação de imagem de empresa que cuida do meio ambiente, ou seja, de uma "empresa verde" ou sustentável, a cada dia mais, as corporações fazem uso do Marketing Verde. Este sustenta a agregação de valor a produtos e serviços que evidenciem responsabilidade social e ambiental das empresas e as diferenciem das demais, promovendo, assim, sua melhor aceitação no mercado (BRASIL, 2012).

Diante de um contexto histórico mais favorável e demandante de ações sustentáveis, serão analisadas, no capítulo seguinte, propostas de sustentabilidade empresarial praticadas pela empresa brasileira O Boticário.

\section{ESTUDO DE CASO E DISCUSSÃO DOS RESULTADOS}

Fundado em 1977, no Paraná, inicialmente como uma farmácia de manipulação, O Boticário, cujos principais produtos são fragrâncias, cremes e artigos de maquiagem, tornouse, segundo classificação do Ibevar ${ }^{2}$ (Instituto Brasileiro de Executivos de Varejo \& Mercado de Consumo) em 2012, a oitava maior empresa varejista do país.

O enfoque da empresa em prol da minimização do impacto ao meio ambiente e da promoção do bem-estar das pessoas teve início em 2012 quando foi criada a Fundação Grupo Boticário de Proteção à Natureza. Esta estipulou estratégias de sustentabilidade empresarial para serem concretizadas na empresa até 2024 relacionadas a consumo de água, de energia, à emissão de gases de efeito estufa e à gestão de resíduos. Além disso, emprega uma prática de logística reversa que é reconhecida como a mais ampla do país.

Os dados a serem apresentados nas subseções seguintes foram recolhidos no site da empresa O Boticário no período de janeiro a julho de 2019 e referem-se ao relatório anual de ecoeficiência empresarial realizado no ano de 2018.

\section{Água}

Em relação ao uso de água, insumo essencial presente em vários processos da cadeia de produção de O Boticário, há uma gestão cuidadosa no programa de metas da empresa objetivando duas linhas de ação principais: a redução do consumo médio por tonelada produzida para 6 metros cúbicos e aumento do reuso para 50\% do total captado. Estas duas propostas se apresentam de forma mais clara na tabela 1:

Tabela 1- Total de água retirada por fonte

\begin{tabular}{|c|c|c|c|c|}
\hline Unidade & $\begin{array}{c}\text { Volume captado } \\
\left(\mathrm{m}^{3}\right) \text { em } 2018\end{array}$ & $\begin{array}{c}\text { Volume } \\
\text { consumido por } \\
\text { tonelada } \\
\left(\mathrm{m}^{3} / \text { ton }\right) \text { em } \\
2018\end{array}$ & $\begin{array}{c}\text { Volume captado } \\
\left(\mathrm{m}^{3}\right) \text { em } 2017\end{array}$ & $\begin{array}{c}\text { Volume } \\
\text { consumido por } \\
\text { tonelada } \\
\left(\mathrm{m}^{3} / \text { ton }\right) \mathrm{em} \\
2017\end{array}$ \\
\hline $\begin{array}{c}\text { Planta São José } \\
\text { dos Pinhais }\end{array}$ & 107.214 & 6,6 & 92.297 & 6,2 \\
\hline $\begin{array}{c}\text { Planta } \\
\text { Camaçari }\end{array}$ & 84.499 & 5,4 & 82.343 & 7,5 \\
\hline $\begin{array}{c}\text { CD Registro } \\
\text { (Poço) }\end{array}$ & 5.741 & 7,0 & 4.713 & 6,3 \\
\hline CD São & 10.151 & 19,9 & 10.100 & 29,3 \\
\hline
\end{tabular}

2 O Instituto Brasileiro de Executivos de Varejo \& Mercado de Consumo é uma instituição sem fins lucrativos. Foi fundada em dezembro de 2009 por um grupo de profissionais ligados ao setor varejista com o objetivo de estabelecer grupos de discussão, relacionamento e conhecimento a respeito deste mercado. 
ESTUDOS DE ADMINISTRAÇÃo E SOCIEDADE V.6, N.1 (2021) 45-61

\begin{tabular}{|c|c|c|c|c|}
\hline Unidade & $\begin{array}{c}\text { Volume captado } \\
\left(\mathrm{m}^{3}\right) \text { em } 2018\end{array}$ & $\begin{array}{c}\text { Volume } \\
\text { consumido por } \\
\text { tonelada } \\
\left(\mathrm{m}^{3} / \text { ton }\right) \text { em } \\
2018\end{array}$ & $\begin{array}{c}\text { Volume captado } \\
\left(\mathrm{m}^{3}\right) \text { em } 2017\end{array}$ & $\begin{array}{c}\text { Volume } \\
\text { consumido por } \\
\text { tonelada } \\
\left(\mathrm{m}^{3} / \text { ton }\right) \text { em } \\
2017\end{array}$ \\
\hline $\begin{array}{c}\text { Gonçalo dos } \\
\text { Campos }\end{array}$ & 207.605 & - & 189.453 & \\
\hline $\begin{array}{c}\text { TOTAL } \\
\text { CONSUMO }\end{array}$ & & & \\
\hline
\end{tabular}

Fonte: relatoriogrupoboticario.com.br/cherry-services/ecoeficiencia/

Fazendo uma comparação entre os anos 2017 e 2018, é possível notar que houve um aumento considerável da água captada na natureza, principalmente na unidade de São José dos Pinhais. Isto se deve ao crescimento da produção de um ano para o outro. Por outro lado, houve redução do volume de água consumido por tonelada, principalmente nas unidades de Camaçari e São Gonçalo dos Campos, o que evidencia uma maior eficiência no processo produtivo. Outro detalhe relevante no que concerne a gestão de água sustentável na empresa é que cerca de $40 \%$ da água consumida nos centros de distribuição foi proveniente de água da chuva.

\section{Energia}

O Boticário, como qualquer outra corporação industrial, tem um grande consumo de energia obtida a partir da queima de combustíveis fósseis, o que desencadeia a emissão de gases de efeito estufa na atmosfera. Em prol da diminuição deste problema, a empresa estabeleceu compromissos a serem cumpridos até o ano de 2024: reduzir o seu consumo e tornar a sua matriz energética totalmente baseada em fontes renováveis; reduzir a dependência de terceiros, por meio da autogeração de energia.

Tabela 2-Taxa de intensidade energética

\begin{tabular}{|c|c|c|}
\hline UNIDADE & $\begin{array}{c}2018 \\
\text { (MWh por milhão de unidades } \\
\text { produzidas) }\end{array}$ & $\begin{array}{c}2017 \\
\text { (MWh por milhão de unidades } \\
\text { produzidas) }\end{array}$ \\
\hline São José dos Pinhais & 107,8 & 101,9 \\
\hline Registro & 18,6 & 13,5 \\
\hline São Gonçalo dos Campos & 19,22 & 27,0 \\
\hline Camaçari & 114,22 & 119,0 \\
\hline
\end{tabular}

Fonte: http://relatoriogrupoboticario.com.br/cherry-services/ecoeficiencia/

Os dados colhidos e mostrados na Tabela 2, assinalam que houve, entre 2017 e 2018 , diminuição do consumo de energia elétrica de $21,7 \%$ no conjunto das unidades por meio de ações do tipo: otimização no sistema de climatização, substituição de lâmpadas convencionais por iluminação em LED. E em relação à intensidade energética, nota-se, pela tabela em seguida que as unidades de São Gonçalo dos Campos e Camaçari obtiveram um considerável aprimoramento no período em questão.

É válido ressaltar que, na produção de cosméticos em O Boticário, as fases que mais consomem energia elétrica são os processos de resfriamento e aquecimento, etapas estas imprescindíveis no manuseio de algumas matérias-primas nesta área. Para adotar uma ação mais sustentável, a empresa adotou a fabricação e o envase a frio para 30 produtos, resultando em uma diminuição em $71 \%$ no tempo de fabricação e na redução de $70 \%$ no consumo de energia elétrica, $15 \%$ no curso de transformação e $10 \%$ no curso de insumos.

\section{Emissões}

A A emissão de gases de efeito estufa na atmosfera é um problema mundial e, em boa parte dos casos, é causado pela queima de combustíveis fósseis na produção industrial. A redução dessas emissões por todos os países é imprescindível para a manutenção da 
biodiversidade e das condições de vida dos homens. Neste contexto, empresas que adotam ações sustentáveis para amenizar este dilema se destacam no mercado e O Boticário é uma delas.

A empresa busca adotar ações que minimizem e a emissão de gases desde a fabricação dos produtos até seu destino final. Anualmente elabora eu inventário de emissões e publica os principais resultados como mostra a tabela 3 .

Tabela 3 - Intensidade das emissões de GEE por unidade operacional.

\begin{tabular}{|l|c|c|c|}
\hline UNIDADE & $\begin{array}{c}2017 \\
\left(\mathrm{tCO} 2 \mathrm{e} / 10^{6} \mathrm{un} . \text { produzidas }\right)\end{array}$ & $\begin{array}{c}2018 \\
\left(\mathrm{tCO} 2 \mathrm{e} / 10^{6} \mathrm{un} . \text { produzidas }\right)\end{array}$ & $\%$ \\
\hline $\begin{array}{l}\text { São José dos } \\
\text { Pinhais }\end{array}$ & 10,2 & 13,3 & $+30 \%$ \\
\hline Registro & 13,9 & 11,5 & $-17 \%$ \\
\hline $\begin{array}{l}\text { São Gonçalo dos } \\
\text { Campos }\end{array}$ & 0,1 & 0,1 & $0 \%$ \\
\hline Camaçari & 1,4 & 0,1 & $-93 \%$ \\
\hline
\end{tabular}

Fonte: http://relatoriogrupoboticario.com.br/cherry-services/ecoeficiencia/

Nota-se, na Tabela 3, que as unidades de São José dos Pinhais e São Gonçalo dos Campos, por estarem em fase de expansão, não diminuíram a emissão de gases no período entre 2017 e 2018. As unidades de Camaçari e Registro. Por outro lado, obtiveram significativa redução de $93 \%$ e $17 \%$, respectivamente, nesta área.

Ainda na perspectiva de ações sustentáveis para a redução da emissão de gases na atmosfera, O Boticário passou a adotar, em algumas linhas de produtos, embalagens de plástico vegetal, fabricado a partir de cana de açúcar, em vez da versão tradicional originário do petróleo. Esta substituição está evitando que sejam lançados na atmosfera 4,95 quilos de CO2 para cada quilo de plástico utilizado no processo de fabricação.

\section{Gestão de resíduos}

Empresas sustentáveis necessitam aplicar ações que visem o mínimo possível de envio de materiais a aterros sanitários. A reciclagem, neste caso, é a palavra-chave. O Boticário, neste contexto, emprega esforços para atingir um patamar de excelência nesta prática como se verifica no Gráfico 1, em que é assinado o aumento, entre os anos 2017 e 2018, da prática de reciclagem de resíduos.

Gráfico 1 - Porcentagem de Resíduos Reciclados

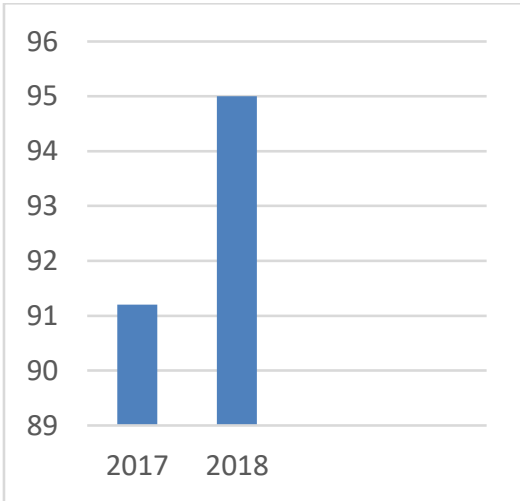

Fonte: http://relatoriogrupoboticario.com.br/cherry-services/ecoeficiencia/

Um projeto interessante desenvolvido na empresa em relação à gestão de resíduos é o Chutando o Balde, que objetiva acabar com a utilização de baldes plásticos no processo de envase de batons, uma vez que a sua reutilização não era possível após esta etapa e eles eram destinados, em sua totalidade, à reciclagem. Por conta disso, foi realizada substituição destes baldes por caixas plásticas, forradas com filme plástico, sendo este descartado, mas aquelas não. Neste projeto, segundo dados fornecidos no site da empresa, 1.5000 baldes deixaram de 
ser utilizados por mês, impedindo a geração de oito toneladas de resíduo por ano.

Outro projeto implementado pela empresa O Boticário para a diminuição de resíduos foi o Caixa Única. Este prevê o reaproveitamento de caixas enviadas por fornecedores de matérias-primas para a linha de produção, o que evitou, segundo dados fornecidos no site da empresa, a geração de 120 toneladas de resíduos de papelão.

Há também uma proposta inovadora relacionada ao uso de um tipo de embalagem que consome menos plásticos que as embalagens tradicionais: o refil. Este recipiente é oferecido em linhas de uso contínuo, tais como maquiagens, desodorantes, loções hidratante s e sabonetes líquidos. E, apenas uma das linhas em que esta prática é dotava, por exemplo, conforme dados fornecidos pelo site da empresa, esta economia chegou a $69 \%$.

Além das ações listadas anteriormente acerca da gestão de resíduos, não se pode deixar de comentar, neste contexto, a aposta da empresa no uso do papel reciclado e em novo formato de caixas. Em relação a primeiro, segundo dados fornecidos no site da empresa, cartuchos de maquiagem lançados em 2018 foram desenvolvidos com este material; e em relação ao segundo, um novo desenho de embalagens de certas linhas de produto associado a uma nova forma de transporte possibilitou a redução de cerca de 50 toneladas de papel por ano. Ressalta-se que esta proposta ganhou o prêmio $\mathrm{ABRE}^{3}$ de embalagens na categoria Sustentabilidade no ano de 2017.

\section{Logística reversa}

A área de logística reversa é um diferencial no grupo O Boticário, que emprega ações sustentáveis não só no processo de fabricação de seus produtos, mas também na destinação das embalagens pós-consumo. Mantendo hoje o maior programa de logística reversa em pontos de coleta no país, desde o ano de 2006, por meio do projeto Bioconsciência, a empresa vem aprimorando tais práticas até que, em 2010, 100\% dos pontos de venda já atuavam na proposta. Pelos resultados obtidos na reciclagem de embalagens, O Boticário foi laureado com o Prêmio ABIHPEC ${ }^{4}$ Beleza Brasil.

Ressalta-se esses resultados evidenciam um programa extremamente eficaz de sustentabilidade. Neste, há 33 cooperativas parceiras que recebem os materiais dando-lhes um descarte adequado; e há transportadoras parceiras, que buscam os produtos dos pontos de coleta e levam-nos para as cooperativas.

Os programas que forma implementados, e avaliados em 2018, visando uma ação de logística reversa sustentável são os seguintes:

- \#botirecicla - como em todas as lojas da rede, há coletores para embalagens para descarte, em 2018, foram feitas quatro campanhas com ação promocional, em que a troca de embalagens vazias rendeu cupons de descontos para compras de novos produtos. Como resultado, parte das embalagens recolhidas se transformou em matéria-prima para itens funcionais e de decoração de loja.

-\#Sustenta+Beauty - proposta permanente em que o consumidor ganha um novo produto a cada cinco embalagens de itens da marca devolvidas. O resultado computado em 2018 (cerca de 1500 trocas) mostrou um crescimento de $20 \%$ no programa e mais de 7 mil embalagens recolhidas.

-\#Chega e Recicla - como em todas as lojas da rede, há coletores para embalagens para descarte, em 2018, foi realizada uma campanha em 10 espaços da representante no Estado de São Paulo. Esta durou 3 meses e teve o seguinte incentivo: a cada 5 embalagens de Eudora devolvidas, a representante ganhava um brinde. Como resultado, foram realizadas mais de 1200 trocas e 6500 embalagens recolhidas.

-\#retornaberê- proposta permanente de incentivo de troca em que o consumidor ganha um batom novo a cada 5 embalagens devolvidas. O resultado computado em 2018 , computou mais de 6.200 trocas com mais de 30.000 embalagens recolhidas, mostrando o crescimento de

3 O prêmio ABRE da Embalagem Brasileira é um prêmio institucional do setor, realizado anualmente para premiar as embalagens que mais se destacaram durante o ano.

4 O Prêmio ABIHPEC é oferecido anualmente pela Associação Brasileira de Indústria de Higiene Pessoal, Perfumaria e Cosméticos para as empresas que se destacaram na área. 
cerca de $120 \%$ no programa.

\section{Considerações Finais}

A necessidade de ações que integrem economia, desenvolvimento e meio ambiente vem sendo discutida, analisada e concretizada em propostas reais desde a Conferência das nações Unidas sobre Desenvolvimento Sustentável no Rio de Janeiro em 1992 (ECO 92). De lá para cá, muitas ações foram sugeridas por políticas públicas e regulamentadas por leis em prol de se desenfrear o desenvolvimento a qualquer custo e efetivar o desenvolvimento sustentável.

No evento do Rio, em 1992, evidenciou-se o estabelecimento de uma nova relação entre o indivíduo e seu meio propiciando a harmonização das questões de âmbito social com as de âmbito ambiental. Houve, então, a proposição de medidas com vistas ao desenvolvimento sustentável no âmbito do crescimento populacional, da garantia de acesso a recursos básicos como água, alimentos e energia a longo prazo, da preservação da biodiversidade e dos ecossistemas, dentre outros temas imprescindíveis para a sociedade. Este foi o grande passo inicial do movimento sustentável no mundo.

Ainda na perspectiva dessa conferência, o documento mais relevante foi a chamada Agenda 21 que popôs uma nova interpretação acerca da ideia de progresso, o qual passou a levar em consideração uma maior harmonia e equilíbrio holístico entre o todo e as partes, promovendo qualidade e quantidade de crescimento. Neste movimento mundial em prol da sustentabilidade, o Brasil adotou importantes resoluções em prol da inclusão social ao propor o efetivo acesso da população à educação, saúde e distribuição de renda, além de projetos de sustentabilidade ambiental tanto na área urbana quanto na rural.

Vinte anos passados, outro grande evento foi realizado no Rio Janeiro, a Rio +20, no qual, após a análise do que foi efetivamente concretizado a partir da primeira conferência, estabeleceram-se novos caminhos da sustentabilidade via novos e emergentes temas. Nesse contexto, a ONU assinalou que a economia verde se constituía uma prática indispensável à sustentabilidade empresarial, uma vez que estabelecia um conjunto de ações nos processos produtivos da sociedade que propiciariam uma melhoria do bem-estar das pessoas em decorrência de uma maior preocupação com a equidade social.

Sobre este assunto, importantes autores se posicionaram e estabeleceram elementos norteadores à sustentabilidade empresarial, tais como Sachs (1993) que estabeleceu as cinco dimensões obrigatórias do desenvolvimento sustentável (social, econômica, ecológica, espacial e cultural) e Dowbor (1998) que vinculou a responsabilidade social das empresas a postura éticas e transparentes.

Com isso, nesse ínterim entre os dois grandes eventos, surgiram inúmeras empresas com propostas de ações sustentáveis em seus processos produtivos. Uma delas foi a indústria brasileira O Boticário que, desde 2012, quando criou a Fundação Grupo Boticário de Proteção à Natureza, direcionou o enfoque da empresa para a minimização do impacto ao meio ambiente e da promoção do bem-estar das pessoas.

Nesta prática, estratégias de sustentabilidade relacionadas ao consumo de água e de energia, à emissão de gases de efeito estufa, à gestão de resíduos e ao descarte de embalagens foram adotadas e trouxeram excelentes resultados. Seu premiado programa de logística reversa é o mais amplo do país. Servindo de modelo para outras empresas, O Boticário foi considerada a empresa mais sustentável do Brasil no ramo de bens de consumo no ano de 2018 .

Nota-se, em última análise, que a sociedade está em um processo sem volta de exigência de adaptação da economia a uma melhor relação com o meio ambiente. O Boticário é um exemplo disso. Não cabe mais, no contexto em que vivemos hoje, o descaso com a natureza. O processo é lento e o caminho é longo, porém é viável.

\section{Referências}

Abramovay, Ricardo. (2010). Desenvolvimento sustentável: qual a estratégia para o Brasil? São Paulo: Novos Estudos CEBRAP.

Amaro, Antonio; Caser, Denise V. A. (2004). Evolução da produtividade na citricultura paulista. 
Informações Econômicas, São Paulo, v. 34, n. 10, p. 7-12.

Ayres, R.U. (2008). Sustainability economics: where do we stand? Ecological Economics, v.67, n.2, p.281310.

Brasil. Ministério do Meio Ambiente. (2003). Construindo a Agenda 21 Local. 2a ed. Brasília.

Senado Federal. (2005). Constituição da República Federativa do Brasil de 5 de outubro de 1988. Constituição Federal. Coletânea de Legislação Administrativa. MEDAUAR, Odete (Org.) 5 ed. rev., atual e ampl. São Paulo: Revista dos Tribunais.

Senado Federal. (2012). Problemas e consensos na Conferência sobre Desenvolvimento Sustentável Rio+20. Disponível em: https://www.senado.gov.br/noticias/Jornal/emdiscussao/rio20/ario20/problemas-e-consensos-na-conferencia-sobre-desenvolvimento-sustentavel-rio20.aspx Acesso em: 03 ago. 2020.

Brown, Lester. (2009). Plano B: 4.0 Mobilização para salvar a civilização. São Paulo: New Content Editora e Produtora.

Carvalho, O.; Viana, O. (1998). Ecodesenvolvimento e equilíbrio ecológico: algumas considerações sobre o Estado do Ceará. Revista Econômica do Nordeste. Fortaleza, v. 29, n. 2.

Comissão Mundial sobre Meio Ambiente e Desenvolvimento. (1991). Nosso Futuro Comum. 2 ed. Rio de Janeiro: Editora da Fundação Getúlio Vargas.

Coral, Elisa. (2002). Modelo de planejamento estratégico para a sustentabilidade empresarial. 2002. $282 \mathrm{f}$. Tese (Doutorado em Engenharia da Produção). Universidade Federal de Santa Catarina, Florianópolis $-\mathrm{SC}$.

Cordani, Umberto G. et.al. (2019). Avaliação das ações brasileiras após a Rio-92. Disponível em: <http://www.scielo.br/scielo.php?pid=S0103-0141997000100019\&script=sci_arttex>t Acesso em: 2 jun. 2019.

Dovers, S.R.; Handmer, J.W. (1992). Uncertainty, sustainability and change. Global Environmental Change, v.2, n.4, p.262-276.

Dowbor, L. A reprodução social. (1998). Proposta para uma gestão descentralizada. Petrópolis: Vozes.

Elkington, J. (2020). Green swans: the coming boom in regenerative capitalism. New York, NY: Fast Company Press.

Freitas, J. (2016). O tributo e o desenvolvimento sustentável. Revista Novos Estudos Jurídicos, 21(3), p. 825-845.

Hoff, Nayar Débora. (2008). A construção do desenvolvimento sustentável através das relações entre as organizações e seus stakeholders: a proposição de uma estrutura analítica. 2008. 425p. Tese (Doutorado em Agronegócios), UFRGS, Porto Alegre.

Horbach, J. (2005). Indicator systems for sustainable innovation. Physica-Verlag, 213p.

Lewis, E.; Lewis, E. (2015). Triple Bottom Line. Organizações e Sustentabilidade, v. 3, p. 272- 285.

Montibeller Filho, Gilberto. (1993). Ecodesenvolvimento e desenvolvimento sustentável: conceitos e princípios. Textos de Economia, vol.4, n.1, Florianópolis, p.131-142.

Mueller, C. (2007). Os Economistas e as relações entre o sistema econômico e o meio ambiente. Brasília: UNB/FINATC.

Organização das Nações Unidas (2021). A ONU e o meio ambiente. Disponível em: https://sustainabledevelopment.un.org/conferences. Acesso em: 03 jul. 2021.

Ramos, A. G. (1989). A nova ciência das organizações: uma reconceituação da riqueza das nações. 2.ed. Rio de Janeiro: FGV.

Rei, F.C.F., Carvalho, S.M. (2012). 25 anos do protocolo de Montreal sobre substâncias que destroem a camada de Ozônio: a experiência do Brasil. Revista Juris da Faculdade de Direito. São Paulo: FAAP, ano IV, volume 8, p.22-27.

Robbins, S. P. (2000). Administração: mudanças e perspectivas. São Paulo: Saraiva.

Sachs, Ignacy. (1986). Espaços, tempos e estratégias do desenvolvimento. São Paulo: Vértice.

(1993). Estratégias de Transição para do século XXI - Desenvolvimento e Meio Ambiente. São Paulo: Studio Nobel - Fundação para o desenvolvimento administrativo.

Sachs, J. D. (2017). A era do desenvolvimento sustentável. Lisboa, Portugal: Conjuntura Actual. 
São Paulo. (2010). Secretaria do Meio Ambiente / Coordenadoria de Planejamento Ambiental. Economia Verde: desenvolvimento, meio ambiente e qualidade de vida no Estado de São Paulo. Coordenação Casemiro Tércio dos Reis Lima Carvalho - São Paulo: SMA/CPLA.

World Commission on Environment and Development. (1987). Our Common Future. Oxford: Oxford University Press. 